\title{
Antidiabetic Effects of Ginseng in Humans and Rodents
}

\author{
Zhanxiang Wang ${ }^{1 *}$ and Hongji Zhang ${ }^{2}$ \\ ${ }^{1}$ Herman B Wells Center for Pediatric Research, Basic Diabetes Group, Department of Pediatrics, Indiana University School of Medicine, USA \\ ${ }^{2}$ Department of Urology, Indiana University School of Medicine, USA
}

\begin{abstract}
Ginseng, one of the most commonly used herbs worldwide, has known anti-hyperglycemic effects. Twenty-eight (28) studies on diabetic mice and rats from 7 research centers (in 6 different nations) indicate that both Asian ginseng (Panax ginseng) and American ginseng (Panax quinquefolius) are effective anti-hyperglycemic supplements, putatively acting via improvements in insulin secretion, insulin sensitivity, islet protection, obesity reduction, antioxidation, energy expenditure, and fat absorption. Investigations in clonal beta-cells (MIN6, RINmF, INS-1, HIT-T15) and non-beta-cells (3T3-L1, C1C12, HepG2) further confirm that ginseng may protect against pancreatic beta-cell apoptosis and promote insulin secretion and glucose uptake. Among 18 human trials from 4 independent groups, 15 are single dose trials; whereas, 4 are long-term trials, with treatment periods lasting longer than 4 weeks. Eleven of the single dose trials observed anti-diabetic effects, while 4 observed no improvements. In the long-term studies, two-thirds of the studies on type 2 diabetic (T2D) patients observed anti-hyperglycemic effects. Based upon the sound evidence from cell lines and animal models, along with the improvements from the majority of human subject trials, ginseng appears to be a potent anti-diabetic supplement. Regardless, more long-term trials on T2D patients are required before ginseng can be safely recommended as a broadly-used anti-diabetic agent.
\end{abstract}

\section{Keywords: MDA; Ginseng; Ginsenoside; Diabetes}

\section{Introduction}

Type 2 diabetes (T2D) is a worldwide epidemic disease. Because commonly prescribed anti-diabetic drugs are riddled with safety concerns and/or have limited efficacy, management of T2D can be challenging. Therefore, alternative medicines, derived from natural products which have very little to no side-effects, offer exciting possibilities for the development of successful anti-diabetic therapies.

Originally used as a stress-reducing tonic for several thousand years in Asia, Ginseng is one of the most popular herbal supplements in the world [1]. In support of ancient Asian wisdom, a number of contemporary researchers have suggested that pharmacological doses of ginseng positively affect the cardiovascular, immune, and central nervous systems $[2,3]$. The primary active components of ginseng are the ginsenosides (ginseng saponins) that comprise 3-6\% of ginseng. Based on their structure, the ginsensosides can be classified into 3 groups: the panaxadiol group (Rb1, Rb2, Rb3, Rc, Rd, Rg3, Rh2); the panaxatriol group (Re, Rf, Rg1, Rg2, Rh1); and the oleanolic group (Ro) $[2,4]$. In China, herbs are routinely used in combination with conventional anti-diabetic therapies to improve hyperglycemia. For single-herb prescriptions, ginseng is the most commonly-used herb: for example, ginseng is one of the top 10 most frequently-prescribed herbs, among the 30 anti-diabetic formulas currently approved by the Chinese government [5]. Intriguing results from basic research have demonstrated that ginseng improves diabetes by enhancing insulin sensitivity, stimulating insulin secretion, protecting pancreatic islets and inhibiting intestinal absorption of carbohydrates [6]. In addition to reliable in vitro and in vivo evidence (Table 1), the majority of reports in human trials also indicate that ginseng administration does indeed have anti-diabetic effects [7-20], though some controversy does exist $[16,21,22]$. In this review, we focus on the anti-diabetic effects of ginseng from both animal and randomized, controlled human studies, discuss possible reasons for the discrepancies among human trials and provide topics for future investigations.

\section{Animal Studies}

\section{Mice}

A number of independent research groups have shown that ginseng has hypoglycemic effects. The majority of the reports are from the Kimura group (Japan), Chung group (South Korea), Yuan group (USA), and Cheng group (Taiwan).

Early in the 1980s, Kimura et al. [23] revealed that ginseng radix (root) extract (10-50 mg/kg) decreased blood glucose and increased blood insulin concentrations in alloxan-induced diabetic mice. Insulin antisera injections abolished these effects, indicating that ginseng-stimulated insulin release is critical for the observed antihyperglycemic effects [23]. A 3-h treatment of ginseng extract $(0.5 \mathrm{mg} /$ $\mathrm{ml})$ stimulated insulin biosynthesis in islets from KK-CAy mice [24]. The Kimura group further observed that the anti-hyperglycemic effect of ginseng was diminished in diabetic KK-CAy and alloxan-induced diabetic mice, if ginseng was combined with anemarrhena or licorice (two additional herbs commonly used in traditional Asian medicine) [25], indicating potential interaction of ginseng with other drugs.

Investigations from Chung and colleagues from South Korea also demonstrated that ginseng has anti-diabetic effects that synergize with the anti-diabetic drug, metformin. Oral administration of white ginseng radix and rootlet for 4 weeks in KKAy mice significantly reduced fasting blood glucose levels, presumably by blocking intestinal glucose absorption [26]. In high fat (HF) diet-fed ICR mice, the Chung group showed that wild ginseng ethanol extract (WGEE, 250 and 500 $\mathrm{mg} / \mathrm{kg}$ ) significantly inhibited body weight gain, fasting blood glucose, triglyceride and free fatty acid levels in a dose-dependent manner. WGEE also improved the insulin resistance index $(>55 \%)$ and decreased white and brown adipocyte diameter $(>46 \%)$ compared to HF-fed controls [27]. A vinegar-processed, as well as non-processed, form of ginseng radix ( $500 \mathrm{mg} / \mathrm{kg} /$ day for 8 weeks) both have significant anti-metabolic

*Corresponding author: Zhanxiang Wang, MD, PhD, 635 Barnhill Dr, MS2031, Herman B Wells Center for Pediatric Research, Department of Pediatrics, Indianapolis, IN 46202, USA, Tel: 317-274-6694; Fax: 317-274-4107; E-mail wangz@iupui.edu

Received January 02, 2012; Accepted March 16, 2012; Published March 26 2012

Citation: Wang Z, Zhang H (2012) Antidiabetic Effects of Ginseng in Humans and Rodents. J Metabolic Synd 1:106. doi:10.4172/2167-0943.1000106

Copyright: () 2012 Wang Z, et al. This is an open-access article distributed under the terms of the Creative Commons Attribution License, which permits unrestricted use, distribution, and reproduction in any medium, provided the original author and source are credited. 


\begin{tabular}{|l|l|l|l|l|}
\hline Groups & Nation & Cell & Ginseng type & Outcome \\
\hline Luo & USA & INS & American Ginseng & Protect apoptosis[66] \\
\hline Chung & Korea & HIT-T15 & Compound K & Increase GSIS[29] \\
\hline & & HIT-T15 & RG3 & Increase GSIS[31] \\
\hline & & RINmF & Fermented ginseng & $\begin{array}{l}\text { Protect apoptosis/Increase } \\
\text { GSIS[67] }\end{array}$ \\
\hline & & MIN6 & Rb1, Rg1 & $\begin{array}{l}\text { Protect apoptosis/Increase } \\
\text { GSIS[68] }\end{array}$ \\
\hline Kim & Korea & MIN6 & Ginseng extract & Protect apoptosis[69] \\
\hline Yuan & USA & MIN6 & Ginseng extract & $\begin{array}{l}\text { Protect apoptosis/lncrease } \\
\text { GSIS[70] }\end{array}$ \\
\hline Shang & China & 3T3-L1 & Rb1 & Increase glucose uptake[71] \\
\hline & & 3T3-L1 & Rb1 & Increase glucose uptake[72] \\
\hline Zhang & China & 3T3-L1 & Re & Activate insulin signaling[73] \\
\hline Jun & Korea & 3T3-L1 & Rb1,Rg1 & Increase glucose uptake[68] \\
\hline Lee & Korea & 3T3-L1 & Rg3,Re & Increase glucose uptake[74] \\
\hline Kwon & Korea & C2C12 & Rc & Increase glucose uptake[75] \\
\hline Chung & Korea & HepG2 & Compound K ${ }^{*}$ & Lipid metabolism[76] \\
\hline & & HepG2 & Rg1 & $\begin{array}{l}\text { Inhibited liver glucose produc- } \\
\text { tion[77] }\end{array}$ \\
\hline Yuan & USA & C2C12 & IH-901* & Stimulation of glucose uptake[78] \\
\hline
\end{tabular}

*: intestine metabolites of ginsenoside

Table 1: Summary of Cell Studies.

syndrome effects in HF-fed ICR mice, with $>81 \%$ decrease in insulin resistance, $>67 \%$ reduction in white adipocytes and a marked inhibition of weight gain (approx. $>53 \%$ ), compared to the HF-fed control animals [28]. Further, in male $\mathrm{db} / \mathrm{db}$ mice treated for 8 weeks, Compound $\mathrm{K}$ (CK), a major intestinal ginsenoside metabolite from the ginseng radix, also exhibited an anti-hyperglycemic effect through increases in insulin secretion, similar to that of sulfonylureas, potent insulin secretagogues. Importantly, the CK $(10 \mathrm{mg} / \mathrm{kg})+$ metformin $(150 \mathrm{mg} / \mathrm{kg})$ group had the lowest insulin resistance index indicating synergistic effects of the drug combination [29]. In a long-term study using C57BL/Ks] $\mathrm{db} / \mathrm{db}$ mice, CK improves oral glucose tolerance, increases insulin release and protects against the destruction of pancreatic islets. CK shifted hepatic glucose metabolism from production to utilization and improved insulin sensitivity by elevating plasma adiponectin levels and up-regulating genes for the glucose transporter and adipogenesis in the adipose tissue [30]. In ICR mice, ginsenoside Rg3 suppressed blood glucose levels by enhancing insulin secretion [31]. In the same ICR mice model, ginseng extract (IH-901 at $25 \mathrm{mg} / \mathrm{kg}$ ) lowered plasma glucose, triglyceride, cholesterol and free fatty acid levels approximately 20.7-41.6\%. Plasma insulin levels were significantly increased between 2.2 and 3.4-fold. Furthermore, histological observation show preserved architecture of the pancreatic islet.

Interesting work from the Yuan group (United States) validated that ginseng berries and leaves are also effective anti-diabetic supplements; juice prepared from the ginseng berry or a water extract of American ginseng can also achieve this goal. Daily intraperitoneal injections of Panax ginseng berry extract $(150 \mathrm{mg} / \mathrm{kg}$ ) in $\mathrm{db} / \mathrm{db}$ mice for 5 consecutive days significantly decreased fasting blood glucose (FBG) levels (180.5 \pm $10.2 \mathrm{mg} / \mathrm{dl}$ vs. control $226.0 \pm 15.3 \mathrm{mg} / \mathrm{dl})$. After 12 days of treatment, the $\mathrm{db} / \mathrm{db}$ mice returned to fasting normoglycemia $(134.3 \pm 7.3 \mathrm{mg} / \mathrm{dl})$, while FBG concentrations in vehicle-treated mice remained high $(254.8$ $\pm 24.1 \mathrm{mg} / \mathrm{dl}$ ). Ginseng-treated mice also lost a significant amount of weight between days 5 and 12. Lean littermates treated with the same dose of ginseng berry extract also lost weight but did not have comparable reductions in FBG [32]. Similar to the $\mathrm{db} / \mathrm{db}$ mouse study, obesediabetic ob/ob mice treated with the ginseng berry extract presented with significant weight loss, reductions in both food intake and plasma cholesterol and increases in energy expenditure and body temperature, compared to lean littermate controls. The ginsenoside Re plays an important role in the anti-hyperglycemic action of ginseng $[33,34]$. The same dose of ginseng berry extract $(150 \mathrm{mg} / \mathrm{kg})$ exhibits more potent anti-hyperglycemic activity, compared to ginseng root extract and only ginseng berry shows marked anti-obesity effects in ob/ob mice [35]. As a more convenient, safe, and practical means of delivery, the Yuan group prepared ginseng berry juice that can be provided orally. Ob/ob mice given ginseng berry juice preparation $(0.6 \mathrm{ml} / \mathrm{kg})$ for 10 consecutive days had significantly lower FBG levels and notable improvements in both glucose tolerance and body weight, which all persisted for at least $10 \mathrm{~d}$ following cessation of the treatment [36]. Daily intraperitoneal injections of extracts from the American ginseng leaf $(50 \mathrm{or} 150 \mathrm{mg} / \mathrm{kg}$ ) in diabetic ob/ob adult mice significantly increased glucose disposal, decreased body weight, and increased body temperature by day 12 of treatment [37]. In ob/ob mice, daily intraperitoneal injections for 12 days of American ginseng root extract (300 mg/kg), prepared by a simple water extraction procedure, significantly improves FBG levels and glucose tolerance, while simultaneously reducing body weight [38]. A research group from Taiwan reported that the hypoglycemic effect of ginseng was only produced in pentobarbital-anesthetized BALB/c and C57BL/6 mice; however, in conscious mice this effect could be achieved only if guanethidine was provided at a sufficient dose to block sympathetic tone [39].

Ginseng also has an inhibitory effect on the absorption of dietary fat in male Balb/c mice [40]. Aerobic exercise plus ginseng appears to lower serum lipid, regulate lipid metabolism, promote anti-oxidation, and enhance immune activity in a mouse model of hyperlipidemia through feeding of a high cholesterol diet [41]. However, in vivo administration of ginseng extract and ginsenosides may cause significant impairment of PPAR $\alpha$-dependent activation of genes involved in the fatty-acid $\beta$-oxidation, suggesting that the use of ginseng be limited under certain pathophysiological conditions, such as hypercholesterolemia [42].

\section{Rats}

Using the rat as research model, a number of independent groups have demonstrated that ginseng has obvious hypoglycemic effects; in a 40 -week study ginseng treatment delayed the development of diabetes. Studies with rats are primarily from four independent groups in Korea, one group from the United States, one from Japan and the Cheng group from Taiwan.

An early report from a Japanese group showed that Ginseng radix fraction $(10-50 \mathrm{mg} / \mathrm{kg})$ increased liver glycogen content, inhibited epinephrine-induced transient hyperglycemia and reduced free fatty acid release from rat epididymal fat pad [43]. Later four independent Korean groups demonstrate that ginseng has anti-obesity effects, which may have beneficial effects on the pathobiology of diabetes. Kim et al. [44] showed that administration of crude saponin from Korean red ginseng $(200 \mathrm{mg} / \mathrm{kg}$, ip) for 3 weeks in obese, male Sprague-Dawley rats (HF diet-induced) significantly reduced body weight, food intake and fat content to levels comparable to that of normal weight, chowfed rats. The hypothalamic NPY expression and serum leptin levels were also reduced in the ginseng-treated HF-fed rats [44]. The results further implicate that the anti-obesity effects of ginseng may result from energy expenditure and normalizing hypothalamic neuropeptides and serum biochemicals related to the control of obesity [45]. Another group from Korea observed that ginseng attenuated the development of overt diabetes. Oral administration of Korean red ginseng (KRG) (200 mg/kg/d) in Otsuka Long-Evans Tokushima Fatty (OLETF) rats for 40 weeks reduced weight gain and visceral fat mass (without altering food intake), improved insulin sensitivity and significantly preserved 
glucose tolerance comparable to control animals for up to 50 weeks of age. KRG promoted fatty acid oxidation in skeletal muscle and cultured C2C12 muscle cells by the AMPK medicated up-regulation of PPARgamma coactivator- 1 alpha, nuclear respiratory factor- 1 , and glucose transporter 4 (GLUT4) [46]. More recent research from the Chung group in Korea further confirmed ginseng's anti-diabetic effect: ginseng provided via an oral or injection route lowers hyperglycemia induced by streptozotocin (STZ) in Sprague Dawley rats. Oral administration of 250 or $500 \mathrm{mg} / \mathrm{kg}$ of fermented ginseng for 20 days (starting one week before STZ injection) reduces plasma glucose level and elevates plasma insulin levels by $266 \%$ and $334 \%$, respectively. STZ-induced destruction of pancreatic islets was hindered, through mechanisms involving reductions of nitric oxide synthase (iNOS) and cyclooxygenase-2 (COX-2) [47].

Research completed by Liu et al. [48] from Taiwan indicates that ginseng may reverse the development of insulin resistance. In rats with insulin resistance induced by the consumption of a high fructose diet, oral administration of Panax ginseng root $(125.0 \mathrm{mg} / \mathrm{kg}$, thrice daily for 3 days) reduced the elevated glucose-insulin index. The plasma glucose concentrations were significantly lower than those of the vehicletreated group. Importantly, the plasma glucose-lowering response of tolbutamide was markedly prolonged in Panax ginseng root treatment group, suggesting that oral administration of Panax ginseng could be a suitable adjuvant therapy for those with insulin resistance [48]. Liu et al. also showed that in high-fat fed Wistar rats plasma glucose is decreased and plasma insulin and C-peptide levels are increased by $60 \mathrm{~min}$ following an intravenous injection of ginsenoside $\mathrm{Rh} 2(0.1-1.0 \mathrm{mg} / \mathrm{kg}) . \mathrm{Rh} 2$ also enhanced insulin secretion mediated by the pancreatic nerve [49]. Intravenous infusion of $\mathrm{Rh} 2$ over $120 \mathrm{~min}$ in STZ-diabetic rats decreased plasma glucose in a dose-dependent manner, while also increasing gene expression of GLUT 4 in soleus muscle [50]. Single intravenous injections of ginsenoside Rh2 in rats with high-fructose diet-induced insulin resistance decreased plasma glucose concentrations, ultimately improving insulin sensitivity [51].

Researchers from the United States recently observed that either acute or chronic administration of ginsenoside $\mathrm{Rb} 1$ is safe and effective in rats. Acute intraperitoneal injections of $\mathrm{Rb} 1$ dose-dependently ( $>5 \mathrm{mg} / \mathrm{kg}$ ) suppressed food intake mediated by central mechanisms (without eliciting signs of toxicity). Additionally, 4-week administration of ginsenoside Rb1 (10 mg/kg) significantly reduced food intake, body weight gain, and body fat content and increased energy expenditure in HFD-induced obese rats. Rb1 also significantly decreased fasting blood glucose and improved glucose tolerance. These effects were greater than those in pair-fed rats, suggesting that the anti-hyperglycemic effect of Rb1 is only partially attributable to reduced food intake and body weight. Importantly, at an effective dose, acute intraperitoneal administration of Rb1 dose-dependently suppressed food intake that was not caused by taste aversion (Table 2) Rb1-treated obese rats also had no obvious health problems, e.g. diarrhea. Additionally, no chronic non-specific toxic effects were observed (assessed by end-study plasma ALT, AST, and creatinine concentrations) [52].

\section{Human Subjects Trials}

Studies investigating the anti-diabetic properties of ginseng in humans have only recently appeared. In this review, we only discuss 18 human trials that are double (or single)-blinded placebo-controlled studies. The majority of these reports indicate that ginseng does indeed have anti-diabetic potential.

In 1995, as a result of their research involving 36 diabetic patients, Sotaniemi et al. [7] suggested that ginseng would be a useful therapeutic adjunct in the management of T2D. Oral ginseng ( 100 or $200 \mathrm{mg} /$ day) for 8 weeks normalized $\mathrm{HbA1c}$ levels, reduced fasting blood glucose concentrations, and reduced body weight, while simultaneously elevating mood and improving psychophysical performance and physical activity [7].

Later, several reports from a group in the United Kingdom confirmed ginseng's effects in regulation of blood glucose in human subjects. In their 3 single-dose trials, involving more than 87 healthy individuals, $200 \mathrm{mg}$ and $400 \mathrm{mg}$ of orally-provided ginseng significantly reduced blood glucose at all three of the post-treatment follow-ups [8-10]. However, the authors were unable to find a long-term effect on glucose regulation when non-diabetic participants $(n=31)$ were provided Panax ginseng for 8 weeks, suggesting against the chronic use of ginseng in individuals with normal glucose control [11].

Multiple reports from a research group in Canada observed that American ginseng (AG) and Korean red ginseng (KRG; Panax ginseng that has been heated) affect postprandial glycemia in humans; the exception being null effects from one batch of AG that had marked decrements in total ginsenosides. In their first report, including 10 nondiabetic subjects, significant reductions in area under the glycemic curve (18 $\pm 31 \%$ ) were observed when ginseng ( $3 \mathrm{~g}$ ) was taken orally $40 \mathrm{~min}$ before the glucose challenge; there were no differences in effect if the ginseng and glucose were administered together. In 9 diabetic patients,

\begin{tabular}{|c|c|c|c|c|}
\hline Groups & Nation & Model & Ginseng type & Research outcome (year) \\
\hline Kimura & Japan & Mice(Alloxan diabetic) & Ginseng extract & $\begin{array}{l}+(1980)[23]+(1981)[43]+(1981)[24] \\
+(1999)[25]\end{array}$ \\
\hline Chung & Korea & $\begin{array}{l}\text { Diabetic mice (KKAy, } \\
\text { ICR, db/db, C57BL/KsJ) } \\
\text { Rat(STZ treated) }\end{array}$ & $\begin{array}{l}\text { Ginseng, Rg3, } \\
\text { compound K, }\end{array}$ & $\begin{array}{l}+(2001)[26]+(2004)[27]+(2007)[28] \\
+(2007)[29]+(2007)[30]+(2008)[31] \\
+(2011)[78] \\
+(2010)[47]\end{array}$ \\
\hline Yuan & USA & Diabetic mice (db/db, ob/ob) & $\begin{array}{l}\text { American Ginseng } \\
\text { extract, berry/leaf/ root }\end{array}$ & $\begin{array}{l}+(2002)[32]+(2002)[33]+(2002)[34] \\
+(2003)[35]+(2004)[37]+(2007)[36] \\
+(2009)[38]\end{array}$ \\
\hline Cheng & Taiwan & $\begin{array}{l}\text { Mice(STZ treated) } \\
\text { Rat(insulin resistant, or STZ treated) }\end{array}$ & $\begin{array}{l}\text { Ginseng } \\
\text { Ginseng, Rh2 }\end{array}$ & $\begin{array}{l}+(2010)[39] \\
+(2005)[48]+(2006)[49]+(2006)[50] \\
+(2007)[51]\end{array}$ \\
\hline Kim & Korea & Rat(fatty,Dawley) & Korea red Ginseng & $+(2005)[44]+(2009)[45]$ \\
\hline Lee & Korea & Rat(fatty,Long-Evans) & Korea red Ginseng & $+(2009)[46]$ \\
\hline Liu & USA & Rat(obese) & $\mathrm{Rb} 1$ & $+(2010)[52]$ \\
\hline
\end{tabular}

+ : indicating antidiabetic effects. 


\begin{tabular}{|c|c|c|c|c|}
\hline Groups & Nation & Human subjects & Ginseng type and dose & Outcome(year) \\
\hline Sotaniemi & Finland & $\mathrm{T} 2 \mathrm{D}(30)$ & Ginseng(100-200mg,8 week oral) & $+(1995)[7]$ \\
\hline Reay & UK & $\begin{array}{l}\text { Norm(30) } \\
\text { Norm(57) } \\
\text { Norm(41) }\end{array}$ & $\begin{array}{l}\text { Ginseng(1 dose, } 200-400 \mathrm{mg} \text { oral) } \\
\text { Ginseng(1 dose) } \\
\text { Ginseng(200mg, } 8 \text { week oral) }\end{array}$ & $\begin{array}{l}+(2005)[8] \\
+(2006)[9][10] \\
-(2009)[11]\end{array}$ \\
\hline Vuksan & Canada & $\begin{array}{l}\text { T2D }(9) \\
\text { T2D }(19) \\
\text { Norm(10) } \\
\text { Norm(10) } \\
\text { Norm(10) } \\
\text { Norm(12) } \\
\text { Norm(12) } \\
\text { Norm(19) } \\
\text { Norm(12) } \\
\text { Norm(13) } \\
\text { Norm(12) } \\
\text { Norm(12) } \\
\text { Norm(22) }\end{array}$ & $\begin{array}{l}\text { American Ginseng( } 1 \text { dose }) \\
\text { Korean red Ginseng }(6 \mathrm{~g} / \mathrm{d}, 12 \text { week oral }) \\
\text { American Ginseng( } 1 \text { dose }) \\
\text { American Ginseng( } 1 \text { dose }) \\
\text { American Ginseng( } 1 \text { dose }) \\
\text { Asian Ginseng(1 dose) } \\
\text { Asian ginseng(1 dose) } \\
\text { Korean red Ginseng (1 dose) } \\
\text { Asian Ginseng(1 dose) } \\
\text { Korean red Ginseng(1 dose) } \\
\text { Asian Ginseng(1 dose) } \\
\text { Asian ginseng(1 dose) } \\
\text { Asian ginseng(1 dose) }\end{array}$ & $\begin{array}{l}+(2000)[12] \\
+(2008)[19] \\
+(2000)[12] \\
+(2000)[13] \\
+(2000)[14] \\
+(2001)[15] \\
+(2004)[16] \\
+(2006)[18] \\
+(2007)[17] \\
+(2011)[20] \\
-(2004)[16] \\
-(2003)[53] \\
-(2003)[54]\end{array}$ \\
\hline Reed & USA & $\mathrm{T} 2 \mathrm{D}(14)$ & Korea red ginseng/Re (3-8g/d, 4 week oral) & - (2011)[22] \\
\hline Others & Japan Korea & & Ginseng extract & $+*[55][56][57]$ \\
\hline
\end{tabular}

*: lipid metabolism; T2D = type 2 diabetes, Norm = healthy people, number of individuals in bracket; 1 dose = 1 single dose experiment. +: positive in antidiabetic effect; -: null in antidiabetic effect.

Table 3: Summary of Human Trials.

AG attenuated postprandial glycemia by similar amount (19 $\pm 22 \%$ and $22 \pm 17 \%$, respectively), regardless if the ginseng administration was before or at same time as the glucose challenge [12]. They further demonstrated that $3 \mathrm{~g}$ AG was sufficient to achieve maximal glucose reduction. AG reduced postprandial glycemia at $30 \mathrm{~min}$ irrespective of dose and time of administration [13]. In non-diabetic individuals, 3, 6 , or $9 \mathrm{~g}$ of $\mathrm{AG}$ (taken 40,80 , or 120 minutes before a glucose challenge) similarly improved glucose tolerance; all treatments reduced area under the incremental glucose curve (26.6\%-38.5\%) [14]. While 1, 2, or $3 \mathrm{~g}$ of AG are equally effective in reductions in glycemia (around $10 \%)$, the blood glucose concentration during the last hour of the test was significantly lower when ginseng was administered 40 min before the challenge, rather than 0,10 , or 20 min pre-glucose challenge [15]. Among the 8 commonly-used ginseng sources (American, Americanwild, Asian, Asian-red, Vietnamese-wild, Siberian, Japanese-rhizome, and Sanchi ginseng), only American ginseng and Vietnamese ginseng lowered plasma glucose at $90 \mathrm{~min}$ in 12 healthy participants given $3 \mathrm{~g}$ of ginseng, while the other species of ginseng had opposite effects, actually elevating glucose levels [16]. American ginseng (9 g) administered 40 min before a 2-h OGTT, also significantly reduced glycemia by $27.7 \%$ and insulin increase by $23.8 \%$, relative to the non-treated control [17]. However, in 2 additional trials, normal subjects were provided Asian ginseng or a different batch of AG (6 g, 40 min prior to a $75 \mathrm{~g}$ OGTT). In these studies, there was no significant effect on the incremental plasma glucose, incremental plasma insulin, or the insulin sensitivity index. However, they found marked decrements in total ginsenosides and $\mathrm{Rb} 1 / \mathrm{Rg} 1$ ratio in those batches of $\mathrm{AG}$, which might be an explanation for the contradictory results $[53,54]$.

When evaluating the different forms of ginseng, Sievenpiper et al. demonstrated that $2 \mathrm{~g}$ of KRG-rootlets ( $40 \mathrm{~min}$ prior to oral glucose test) is sufficient to achieve reproducible reductions (29\%) in postprandial glycemia [18]. Long-term outcomes (efficacy and safety) of KRG are also encouraging. Nineteen well-controlled type 2 diabetics (sex: $11 \mathrm{M}, 8 \mathrm{~F}$; age: $64 \pm 2$ years) took 2 g KRG (total 6 g/day) 40 min prior to each meal for 12 weeks as an adjunct to their usual antidiabetic therapy (diet and/or medications). Improvements in glycemic control were observed; although $\mathrm{HbAlc}$ did not improve, plasma glucose was reduced by $8-11 \%$, fasting and OGTT plasma insulin was increased y 33-38\%, and insulin sensitivity increased by 33\%, compared with placebo-treated controls [19]. Interestingly, the KRG rootlets had $>6$-fold more total ginsenosides than the KRG-body, but did not significantly affect postprandial glucose. However, despite this reduced ginsenoside profile, KRG-body lowered postprandial glucose levels at $45,60,90$, and $120 \mathrm{~min}$ during the glucose tolerance test, rendering an overall reduction of $27 \%$ (AUC) compared to the control ( $\mathrm{p}<0.05$ ). This suggests a potential therapeutic dose range for ginsenosides [20].

However, more recent research from a group in the United States observed no anti-diabetic effect from AG. Fifteen overweight or obese subjects (sex: $14 \mathrm{~F}, 1 \mathrm{M} ; \mathrm{BMI}=34 \pm 1$; age $=46 \pm 3 \mathrm{yr}$ ) with impaired glucose tolerance or newly diagnosed T2D were randomized to 30 days of treatment with ginseng root extract ( $8 \mathrm{~g} /$ day), ginsenoside Re (250-500 mg/day), or placebo. Beta cell function was assessed as the disposition index (DI); oral glucose tolerance test and insulin sensitivity (IS) were also monitored. Values for DI and IS were not different among the placebo, ginseng, and ginsenoside Re-treated groups. Ginsenosides $\mathrm{Re}, \mathrm{Rb}_{1}$, and $R \mathrm{~b}_{2}$ were not detectable in plasma after treatment with ginseng root extract or ginsenoside Re (Table 3). They argued that poor systemic bioavailability might be responsible for the absence of a therapeutic effect [22].

In addition to blood glucose regulatory effect, oral administration of ginseng has also been observed to have effects on lipid metabolism in human [55-57].

\section{Discussion}

In the development of $\mathrm{T} 2 \mathrm{D}$, both islet beta-cell dysfunction and muscle insulin resistance play important roles [58,59]. Evidence from cell studies indicates that ginseng (both Asian ginseng [Panax ginseng] and American ginseng [Panax quinquefolius]) could protect islet betacell function and enhance glucose uptake, both supportive of ginseng being a potent anti-diabetic supplement. Twenty-eight animal studies from seven different international research groups confirm these effects and suggest ginseng may delay diabetes progression. In vivo anti-hyperglycemia mechanisms of ginseng involve increased insulin secretion, insulin sensitization and islet protection with additional antiobesity, anti-oxidation, energy expenditure and glucose absorption effects. Interestingly, ginseng is found to synergize with metformin but may have adverse interactions with other herbs. Positive outcomes from long-term studies ( $>40$ weeks) indicate ginseng may be beneficial for chronic use in diabetic individuals. Overall, evidence-based data 
acquired from animal studies support the anti-diabetic effects of ginseng.

In human studies, among 18 trials (299 human subjects) from four research groups, only 4 trials ( 74 cases) are T2D patients, with most being non-diabetic volunteers; In addition, only 4 studies are long-term ( $>4$ weeks) trials. The majority, if not all, of one dose trials observed anti-hyperglycemic effects for both American ginseng and Panax ginseng. In three long-term independent trials with T2D patients, two trials demonstrated positive effects (invovling 30 patients) [7], while one showed no effects (involving 14 patients) [19]. The failure to observe anti-diabetic effects in some of the human trials may be due to the difference in batches of Ginseng used, of which ginsenoside levels may differ. Yet, the genetic and metobolic differences of human subjets among the trial groups should also be considerd. Since drug pharmacokinetic and pharmacodynamic differences exist among different populations $[60,61]$ and between genders $[61,62]$. Different response rates to specific drugs also exist [63], even the gut microbiome (important for human health) could be different due to genetic background, gender [64] and diet habits [65]. Thus, different populations may absorb/metaoblize ginseng differently, which would affect the bioavailability of the effective compounds in Ginseng. Therefore in the future, while more T2D patients and research centers are inclined to participte in ginseng trials, it is also necessary to investigate the pharmacodynamic differences of ginseng among different populations. In Chinese medicine, ginseng is primarily administered in low doses in combination with other herbs for synergistic effects, therefore it will also be necessary to define how ginseng synergizes with other natural dietary supplements or with routinely used anti-diabetic drugs in diabetes treatment.

\section{Acknowledgement}

Zhanxiang Wang analyzed data and wrote the manuscript; Hongji Zhang collected and analyzed data, as well as helped in discussion. We thank Dr. Stephanie Yoder for critical reading of the manuscript. This study is partially supported by grant from the National Institutes of Health (CTSI-KL2 RR025760 to ZW).

\section{References}

1. Bahrke MS, Morgan WP, Stegner A (2009) Is ginseng an ergogenic aid? Int J Sport Nutr Exerc Metab 19: 298-322.

2. Attele AS, Wu JA, Yuan CS (1999) Ginseng pharmacology: multiple constituents and multiple actions. Biochem Pharmacol 58: 1685-1693.

3. Yuan CS, Wu JA, Osinski J (2002) Ginsenoside variability in American ginseng samples. Am J Clin Nutr 75: 600-601.

4. Xiang $Y Z$, Shang $H C$, Gao XM, Zhang BL (2008) A comparison of the ancient use of ginseng in traditional Chinese medicine with modern pharmacological experiments and clinical trials. Phytother Res 22: 851-858.

5. Xie W, Zhao $Y$, Zhang $Y$ (2011) Traditional chinese medicines in treatment of patients with type 2 diabetes mellitus. Evid Based Complement Alternat Med 726723.

6. Yin J, Zhang $\mathrm{H}$, Ye $\mathrm{J}$ (2008) Traditional chinese medicine in treatment of metabolic syndrome. Endocr Metab Immune Disord Drug Targets 8: 99-111.

7. Sotaniemi EA, Haapakoski E, Rautio A (1995) Ginseng therapy in non-insulindependent diabetic patients. Diabetes Care 18: 1373-1375.

8. Reay JL, Kennedy DO, Scholey AB (2005) Single doses of Panax ginseng (G115) reduce blood glucose levels and improve cognitive performance during sustained mental activity. J Psychopharmacol 19: 357-365.

9. Reay JL, Kennedy DO, Scholey AB (2006) The glycaemic effects of single doses of Panax ginseng in young healthy volunteers. Br J Nutr 96: 639-642.

10. Reay JL, Kennedy DO, Scholey AB (2006) Effects of Panax ginseng, consumed with and without glucose, on blood glucose levels and cognitive performance during sustained 'mentally demanding' tasks. J Psychopharmacol 20: 771-781.

11. Reay JL, Scholey AB, Milne A, Fenwick J, Kennedy DO (2009) Panax ginseng has no effect on indices of glucose regulation following acute or chronic ingestion in healthy volunteers. Br J Nutr 101: 1673-1678.

12. Vuksan V, Sievenpiper JL, Koo VY, Francis T, Beljan-Zdravkovic U, et al. (2000) American ginseng (Panax quinquefolius $\mathrm{L}$ ) reduces postprandial glycemia in nondiabetic subjects and subjects with type 2 diabetes mellitus. Arch Intern Med 160: 1009-1013.

13. Vuksan V, Stavro MP, Sievenpiper JL, Koo VY, Wong E, et al. (2000) American ginseng improves glycemia in individuals with normal glucose tolerance: effect of dose and time escalation. J Am Coll Nutr 19: 738-744.

14. Vuksan V, Stavro MP, Sievenpiper JL, Beljan-Zdravkovic U, Leiter LA, et al. (2000) Similar postprandial glycemic reductions with escalation of dose and administration time of American ginseng in type 2 diabetes. Diabetes Care 23 1221-1226.

15. Vuksan V, Sievenpiper JL, Wong J, Xu Z, Beljan-Zdravkovic U, et al. (2001) American ginseng (Panax quinquefolius L.) attenuates postprandial glycemia in a time-dependent but not dose-dependent manner in healthy individuals. Am J Clin Nutr 73: 753-758.

16. Sievenpiper JL, Arnason JT, Leiter LA, Vuksan V (2004) Decreasing, null and increasing effects of eight popular types of ginseng on acute postprandia glycemic indices in healthy humans: the role of ginsenosides. J Am Coll Nutr 23: $248-258$.

17. Dascalu A, Sievenpiper JL, Jenkins AL, Stavro MP, Leiter LA, et al. (2007) Five batches representative of Ontario-grown American ginseng root produce comparable reductions of postprandial glycemia in healthy individuals. Can $J$ Physiol Pharmacol 85: 856-864.

18. Sievenpiper JL, Sung MK, Di Buono M, Seung-Lee K, Nam KY, et al. (2006) Korean red ginseng rootlets decrease acute postprandial glycemia: results from sequential preparation- and dose-finding studies. J Am Coll Nutr 25: 100-107.

19. Vuksan V, Sung MK, Sievenpiper JL, Stavro PM, Jenkins AL, et al. (2008) Korean red ginseng (Panax ginseng) improves glucose and insulin regulation in well-controlled, type 2 diabetes: results of a randomized, double-blind, placebocontrolled study of efficacy and safety. Nutr Metab Cardiovasc Dis 18: 46-56.

20. De Souza LR, Jenkins AL, Sievenpiper JL, Jovanovski E, Rahelic D, et al. (2011) Korean red ginseng (Panax ginseng C.A. Meyer) root fractions: Differential effects on postprandial glycemia in healthy individuals. J Ethnopharmacol 137 245-250.

21. Sievenpiper JL, Arnason JT, Vidgen E, Leiter LA, Vuksan V (2004) A systematic quantitative analysis of the literature of the high variability in ginseng (Panax spp.): should ginseng be trusted in diabetes? Diabetes Care 27: 839-840.

22. Reeds DN, Patterson BW, Okunade A, Holloszy JO, Polonsky KS, et al. (2011) Ginseng and ginsenoside $\mathrm{Re}$ do not improve beta-cell function or insulin sensitivity in overweight and obese subjects with impaired glucose tolerance or diabetes. Diabetes Care 34: 1071-1076.

23. Kimura M, Waki I, Chujo T, Kikuchi T, Hiyama C, et al. (1981) Effects of hypoglycemic components in ginseng radix on blood insulin level in alloxan diabetic mice and on insulin release from perfused rat pancreas. $J$ Pharmacobiodyn 4: 410-417.

24. Waki I, Kyo H, Yasuda M, Kimura M (1982) Effects of a hypoglycemic component of ginseng radix on insulin biosynthesis in normal and diabetic animals. J Pharmacobiodyn 5: 547-554.

25. Kimura I, Nakashima N, Sugihara Y, Fu-jun C, Kimura M (1999) The antihyperglycaemic blend effect of traditional chinese medicine byakko-kaninjin-to on alloxan and diabetic KK-CA(y) mice. Phytother Res 13: 484-488.

26. Chung SH, Choi CG, Park SH (2001) Comparisons between white ginseng radix and rootlet for antidiabetic activity and mechanism in KKAy mice. Arch Pharm Res 24: 214-218.

27. Yun SN, Moon SJ, Ko SK, Im BO, Chung SH (2004) Wild ginseng prevents the onset of high-fat diet induced hyperglycemia and obesity in ICR mice. Arch Pharm Res 27: 790-796.

28. Yun SN, Ko SK, Lee KH, Chung SH (2007) Vinegar-processed ginseng radix improves metabolic syndrome induced by a high fat diet in ICR mice. Arch Pharm Res 30: 587-595.

29. Yoon SH, Han EJ, Sung JH, Chung SH (2007) Anti-diabetic effects of compound $\mathrm{K}$ versus metformin versus compound $\mathrm{K}$-metformin combination therapy in diabetic db/db mice. Biol Pharm Bull 30: 2196-2200.

30. Han GC, Ko SK, Sung JH, Chung SH (2007) Compound K enhances insulin 
secretion with beneficial metabolic effects in $\mathrm{db} / \mathrm{db}$ mice. J Agric Food Chem 55: 10641-10648.

31. Park MW, Ha J, Chung SH (2008) 20(S)-ginsenoside Rg3 enhances glucosestimulated insulin secretion and activates AMPK. Biol Pharm Bull 31: 748-751.

32. Xie JT, Zhou YP, Dey L, Attele AS, Wu JA, et al. (2002) Ginseng berry reduces blood glucose and body weight in db/db mice. Phytomedicine 9: 254-258.

33. Attele AS, Zhou YP, Xie JT, Wu JA, Zhang L, et al. (2002) Antidiabetic effects of Panax ginseng berry extract and the identification of an effective component. Diabetes 51: 1851-1858.

34. Xie JT, Aung HH, Wu JA, Attel AS, Yuan CS (2002) Effects of American ginseng berry extract on blood glucose levels in ob/ob mice. Am J Chin Med 30: 187194

35. Dey L, Xie JT, Wang A, Wu J, Maleckar SA, et al. (2003) Anti-hyperglycemic effects of ginseng: comparison between root and berry. Phytomedicine 10: 600605

36. Xie JT, Wang CZ, Ni M, Wu JA, Mehendale SR, et al. (2007) American ginseng berry juice intake reduces blood glucose and body weight in ob/ob mice. J Food Sci 72: S590-S594.

37. Xie JT, Mehendale SR, Wang A, Han AH, Wu JA, et al. (2004) American ginseng leaf: ginsenoside analysis and hypoglycemic activity. Pharmacol Res 49: 113-117.

38. Xie JT, Wang CZ, Li XL, Ni M, Fishbein A, et al. (2009) Anti-diabetic effect of American ginseng may not be linked to antioxidant activity: comparison between American ginseng and Scutellaria baicalensis using an ob/ob mice model. Fitoterapia 80: 306-311.

39. Lee KS, Yu WJ, Wang MJ, Wu HT, Chang CH, et al. (2010) Autonomic regulation of insulin secretion is changed by pentobarbital in mice. Neurosci Lett 479: 6-9.

40. Karu N, Reifen R, Kerem Z (2007) Weight gain reduction in mice fed Panax ginseng saponin, a pancreatic lipase inhibitor. J Agric Food Chem 55: 2824 2828.

41. Yang Y, Wu T, He K, Fu ZG (1999) Effect of aerobic exercise and ginsenosides on lipid metabolism in diet-induced hyperlipidemia mice. Zhongguo Yao Li Xue Bao 20: 563-565.

42. Yoon M, Lee H, Jeong S, Kim JJ, Nicol CJ, et al. (2003) Peroxisome proliferatoractivated receptor alpha is involved in the regulation of lipid metabolism by ginseng. Br J Pharmacol 138: 1295-1302.

43. Kimura M, Waki I, Tanaka O, Nagai Y, Shibata S (1981) Pharmacological sequential trials for the fractionation of components with hypoglycemic activity in alloxan diabetic mice from ginseng radix. J Pharmacobiodyn 4: 402-409.

44. Kim JH, Hahm DH, Yang DC, Kim JH, Lee HJ, et al. (2005) Effect of crude saponin of Korean red ginseng on high-fat diet-induced obesity in the rat. $J$ Pharmacol Sci 97: 124-131.

45. Kim JH, Kang SA, Han SM, Shim I (2009) Comparison of the antiobesity effects of the protopanaxadiol- and protopanaxatriol-type saponins of red ginseng. Phytother Res 23: 78-85.

46. Lee HJ, Lee YH, Park SK, Kang ES, Kim HJ, et al. (2009) Korean red ginseng (Panax ginseng) improves insulin sensitivity and attenuates the development of diabetes in Otsuka Long-Evans Tokushima fatty rats. Metabolism 58: 11701177.

47. Yuan HD, Chung SH (2010) Fermented ginseng protects streptozotocininduced damage in rat pancreas by inhibiting nuclear factor-kappaB. Phytother Res 24: S190-S195.

48. Liu TP, Liu IM, Cheng JT (2005) Improvement of insulin resistance by panax ginseng in fructose-rich chow-fed rats. Horm Metab Res 37: 146-151.

49. Lee WK, Kao ST, Liu IM, Cheng JT (2006) Increase of insulin secretion by ginsenoside Rh2 to lower plasma glucose in Wistar rats. Clin Exp Pharmaco Physiol 33: 27-32.

50. Lai DM, Tu YK, Liu IM, Chen PF, Cheng JT (2006) Mediation of beta-endorphin by ginsenoside Rh2 to lower plasma glucose in streptozotocin-induced diabetic rats. Planta Med 72: 9-13

51. Lee WK, Kao ST, Liu IM, Cheng JT (2007) Ginsenoside Rh2 is one of the active principles of Panax ginseng root to improve insulin sensitivity in fructose-rich chow-fed rats. Horm Metab Res 39: 347-354.

52. Xiong Y, Shen L, Liu KJ, Tso P, Wang G, et al. (2010) Antiobesity and antihyperglycemic effects of ginsenoside Rb1 in rats. Diabetes 59: 2505-2512.

53. Sievenpiper JL, Arnason JT, Leiter LA, Vuksan V (2003) Variable effects of American ginseng: a batch of American ginseng (Panax quinquefolius L.) with a depressed ginsenoside profile does not affect postprandial glycemia. Eur $J$ Clin Nutr 57: 243-248.

54. Sievenpiper JL, Arnason JT, Leiter LA, Vuksan V (2003) Null and opposing effects of Asian ginseng (Panax ginseng C.A. Meyer) on acute glycemia: results of two acute dose escalation studies. J Am Coll Nutr 22: 524-532.

55. Kim SH, Park KS (2003) Effects of Panax ginseng extract on lipid metabolism in humans. Pharmacol Res 48: 511-513.

56. Yamamoto M, Uemura T, Nakama S, Uemiya M, Kumagai A (1983) Serum HDL-cholesterol-increasing and fatty liver-improving actions of Panax ginseng in high cholesterol diet-fed rats with clinical effect on hyperlipidemia in man. Am J Chin Med 11: 96-101.

57. Yamamoto M, Kumagai A, Yamamura Y (1983) Plasma lipid-lowering action of ginseng saponins and mechanism of the action. Am J Chin Med 11: 84-87.

58. DeFronzo RA (2010) Current issues in the treatment of type 2 diabetes. Overview of newer agents: where treatment is going. Am J Med 123: S38-S48.

59. Marchetti P, Lupi R, Del Guerra S, Bugliani M, Marselli L, et al. (2010) The betacell in human type 2 diabetes. Adv Exp Med Biol 654: 501-514.

60. Takahashi H, Wilkinson GR, Nutescu EA, Morita T, Ritchie MD, et al. (2006) Different contributions of polymorphisms in VKORC1 and CYP2C9 to intraand inter-population differences in maintenance dose of warfarin in Japanese, Caucasians and African-Americans. Pharmacogenet Genomics 16: 101-110.

61. Donovan MD (2005) Sex and racial differences in pharmacological response: effect of route of administration and drug delivery system on pharmacokinetics. J Womens Health (Larchmt) 14: 30-37.

62. Anderson GD (2005) Sex and racial differences in pharmacologica response: where is the evidence? Pharmacogenetics, pharmacokinetics, and pharmacodynamics. J Womens Health (Larchmt) 14: 19-29.

63. Ripley E, King K, Sica DA (2000) Racial differences in response to acute dosing with hydrochlorothiazide. Am J Hypertens 13: 157-164.

64. Kovacs A, Ben-Jacob N, Tayem H, Halperin E, Iraqi FA, et al. (2011) Genotype is a stronger determinant than sex of the mouse gut microbiota. Microb Ecol 61: 423-428.

65. Wu GD, Chen J, Hoffmann C, Bittinger K, Chen YY, et al. (2011) Linking longterm dietary patterns with gut microbial enterotypes. Science 334: 105-108.

66. Luo JZ, Luo L (2006) American ginseng stimulates insulin production and prevents apoptosis through regulation of uncoupling protein-2 in cultured beta cells. Evid Based Complement Alternat Med 3: 365-372.

67. Yuan HD, Chung SH (2010) Protective effects of fermented ginseng on streptozotocin-induced pancreatic beta-cell damage through inhibition of NFkappaB. Int J Mol Med 25: 53-58

68. Park S, Ahn IS, Kwon DY, Ko BS, Jun WK (2008) Ginsenosides Rb1 and Rg1 suppress triglyceride accumulation in 3T3-L1 adipocytes and enhance beta-cell insulin secretion and viability in Min6 cells via PKA-dependent pathways. Biosci Biotechnol Biochem 72: 2815-2823.

69. Kim HY, Kim K (2007) Protective effect of ginseng on cytokine-induced apoptosis in pancreatic beta-cells. J Agric Food Chem 55: 2816-2823.

70. Lin E, Wang Y, Mehendale S, Sun S, Wang CZ, et al. (2008) Antioxidant protection by American ginseng in pancreatic beta-cells. Am J Chin Med 36: 981-988.

71. Shang $W$, Yang $Y$, Jiang $B$, Jin $H$, Zhou L, et al. (2007) Ginsenoside Rb1 promotes adipogenesis in 3T3-L1 cells by enhancing PPARgamma2 and $\mathrm{C} /$ EBPalpha gene expression. Life Sci 80: 618-625.

72. Shang W, Yang Y, Zhou L, Jiang B, Jin H, et al. (2008) Ginsenoside Rb1 stimulates glucose uptake through insulin-like signaling pathway in 3T3-L adipocytes. J Endocrinol 198: 561-569.

73. Zhang Z, Li X, Lv W, Yang Y, Gao H, et al. (2008) Ginsenoside Re reduces insulin resistance through inhibition of C-Jun $\mathrm{NH} 2$-terminal kinase and nuclear factor-kappaB. Mol Endocrinol 22: 186-195.

74. Lee $\mathrm{OH}$, Lee $\mathrm{HH}$, Kim JH, Lee BY (2011) Effect of ginsenosides Rg3 and Re on glucose transport in mature 3T3-L1 adipocytes. Phytother Res 25: 768-773.

75. Lee MS, Hwang JT, Kim SH, Yoon S, Kim MS, et al. (2010) Ginsenoside Rc, 
an active component of Panax ginseng, stimulates glucose uptake in $\mathrm{C} 2 \mathrm{C} 12$ myotubes through an AMPK-dependent mechanism. J Ethnopharmacol 127: 771-776.

76. Kim do Y, Yuan HD, Chung IK, Chung SH (2009) Compound K, intestinal metabolite of ginsenoside, attenuates hepatic lipid accumulation via AMPK activation in human hepatoma cells. J Agric Food Chem 57: 1532-1537.
77. Kim SJ, Yuan HD, Chung SH (2010) Ginsenoside Rg1 suppresses hepatic glucose production via AMP-activated protein kinase in HepG2 cells. Biol Pharm Bull 33: 325-328.

78. Yuan HD, Kim SJ, Chung SH (2011) Beneficial effects of IH-901 on glucose and lipid metabolisms via activating adenosine monophosphate-activated protein kinase and phosphatidylinositol-3 kinase pathways. Metabolism 60: 43-51. 